\title{
Introduction to the second issue of the revitalized World Nutrition
}

We are pleased to present the second edition of the re-instituted WPHNA (wphna.org) journal World Nutrition. Like the first one, it benefits from the work of many scientists around the world, including a couple dozen unsung volunteer peer reviewers. There was one issue of WN in 2016, two in 2017 (though they provided 330 pages of content), and we hope for three or four in 2018.

We are even more pleased to see an increasing number of authors of more academically-oriented papers choosing to publish in WN. For such papers (and evidence-based commentary), we use a doubleblind peer review process. There is no charge to authors or readers, with all financial aspects of the journal free from conflicts of interest, paid for by WPHNA membership fees. Each article is assigned a permanent DOI and is thus searchable on Google Scholar and other academic website. We invite prospective authors and reviewers to register and submit directly to the online journal at https://worldnutritionjournal.org/index.php/wn/about/submissions Here you will find instructions for authors, but you can always write directly to me with any questions before or during the submission process.

The entire WN archive can now be accessed via the new website. Our search function is based on the metadata entered by authors, so enter as much as possible in the key words and abstract boxes. The search engine is not very effective in locating articles in the archive, however, as they have little or no metadata.

The current issue begins with Kent's Good Questions; reader inputs are cordially invited. Our previous issue focused attention on agriculture and food, a major pillar on which nutrition rests, yet somehow forgotten in the corporate-directed magic bullet narrative now in vogue among major international funders. This focus is deepened through four articles in the current issue.

The first relates to vitamin A deficiency (VAD), the topic of the first commentary in this journal, published in 2010

(http://www.wphna.org/htdocs/downloads/WPHNA web commentary may2010.pdf) and of many follow up letters and articles published in later issues of WN. This first article in the current issue was written by me. As is done by editors for other journals, its peer review process was handled by our deputy editor, George Kent. After spending many months in reviewing and summarizing the scientific literature published since 1992, I can dare to claim that it is by far the most comprehensive paper ever published that reviews data separately on the efficacy (Table 1) and effectiveness (Table 2) of the foodbased approach. It thus gathers in one place information that researchers and program designers will find nowhere else.

Second, Shrimpton adds another weighty literature review, this one on the food system and its sustainability, in particular its links to the Sustainable Development Goals. Third, Schuftan contributes a review of the $10^{\text {th }}$ Anniversary issue of Right to Food and Nutrition Watch. Many are unaware, not only that food and nutrition are human rights, but that the entire issue of human rights has gradually taken center stage in the ongoing global struggle for democracy and human dignity. 
Fourth, we tend to forget that the first component of all efforts to protect food security should focus on protecting, supporting, normalizing and promoting breastfeeding. For those who cannot be breast fed, by far the best alternative is breast milk feeding. Kent explores ways in which the availability of breast milk could greatly be expanded globally.

Next, Ines et al provide perhaps the first study to examine the role of gender roles in creating barriers to access to Community Management of Acute Malnutrition (CMAM). Then we reprint an important perspective by Chowdhury and Sundaram on how the global trade architecture keeps Africa in a perpetual state of hunger. Khandelwal et al provide an in-depth analysis of what is being taught in postgraduate nutrition in India.

Our last issue also dealt in several ways with corporate creep, perhaps more correctly corporate takeover. Clark takes us into the specific aspect of infant feeding and avoiding conflicts of interest in that critical area of public health nutrition. lonata et al reveal how infant food companies use the same tactics as the tobacco industry to confound governments and everyone else, avoiding regulations that might limit their profits, even if they save lives. Jacobson focuses on corporate promotion of sugary drinks in low-income countries.

Probably the most sophisticated and long-running public health nutrition group to challenge corporate power is IBFAN (International Baby Food Action Network). In this issue we publish a review by Ching of their annual report on what the baby food companies are up to. Though this is their main focus, they work on several other issues (see the article on endocrine disruptor chemicals in our last issue) and have helped train networks working on still other issues. We ask readers to consider contributing to this critical bastion against corporate take over here: https://www.ibfan-icdc.org/donate/ Please use the offer code [NUTRITIONJOURNAL2017].

We wish all our readers a happy holiday season.

Ted Greiner

Editor-in-Chief

World Nutrition 